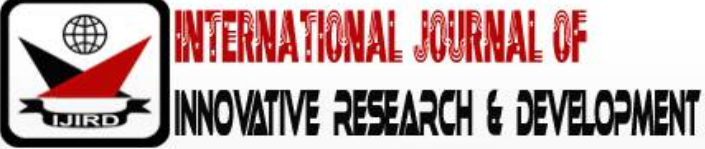

ISSN 2278 - 0211 (Online)

\section{Gender Disparity between Boys and Girls in the Performance of Mathematics in the Krachi East Municipality, Ghana}

\begin{tabular}{c}
\hline Patrick Kwabena Amoakoh \\
Tutor, Department of Mathematics \& ICT, OLA College of Education, Cape Coast, Ghana \\
Samuel Abotowuro \\
Tutor, Department of Mathematics \& ICT, Dambai College of Education, Dambai, Ghana \\
\hline
\end{tabular}

\begin{abstract}
:
The quality of teaching and learning of mathematics with girls having equal opportunities with their counterpart boys has one of the major challenges and concerns of educators. The 1960's, up to date gender disparity in mathematics performance has been a major topic also for educational and mathematical research. This study is concern with gender disparity analysis of pupils in mathematics performance as determined by the basic skills in mathematics, in the public schools in the Krachi East Municipality.

Pupils enrolled from class one to the Junior High Schools, an analysis of variance found a significant difference in the total mathematics achievement across the gender desk. Additional analysis of variance revealed statistically significant difference in mathematics performance favouring boys over females with $\mathrm{p}<0.0011$.

Additional Analysis of variance revealed statistically significant differences in mathematics performance favouring boys over females with $p<005$. Explanations for this particular result have been attributed to some social issues including Socio Economics Status, teacher's student relationships account for gender disparity in mathematics achievement favouring boys and visible role models presented by the performance in the students favouring males. When accounting for the social situations of this population, the findings are commensurate with previous studies done on this type of population.
\end{abstract}

Keywords: Gender, disparity

\section{Introduction}

Mathematics as a subject and a basis to the development of any developed nation cannot be left out from the educational curriculum of any country in which case Ghana is not an exception because it helps us in diverse ways. Mathematics helps us to develop in the field of science and technology and how to understand exactly how our universe works. According to American Heritage Dictionary (2000), Mathematics is the study of measurement, properties and sets using numbers and symbols.

Wlfram Mathwor (1989) mathematics is the study in which the properties and interaction of idealize objects are examined. However, Mathematics has not yielded the desire outcome in the Krachi East Municipal of Ghana. Mathematics has been paraded by most female students as very difficult, as a result, most students tend to perform in the subject poorly both in their end of term examination and Basic Education Certificate Examination. Many female students also dropout of school due to the perceived difficult of the subject; and related lack of interest in mathematics at the basic school level. Most female students as compare to their counter parts boys find the concept very difficult at the basic level in Mathematics. Fraction is no exception. Fraction as a concept can never be left out. All the philosophical thinkers such as Aristotle, plato use fractions to solve problems of complexities they face on the earth and this therefore shows that, Ghana as a developing country needs to embrace Mathematics to develop. Mathematics is perceived by most institutions and societies as the foundation for scientific and technological development that is cherished by societies worldwide. It is an instruction for political, socio-economic, scientific and technological developments (Githua\&Mwangi, 2003). This does explain why Mathematics is a compulsory subject for all learner in the primary schools in Ghana. Kerlinge (1985) describes Mathematics as a language of sciences, but essential nutrient for thought, logical reasoning and progress Mathematics liberates the mind and also gives individuals and assessment of the intellectual abilities towards direction of improvement. endeavours.

The author concludes by saying that, Mathematics is the basics of all science and technology and of all human

Application of Mathematics cuts across all areas of human knowledge (Aminu 1990). The Ghana Mathematics syllabus is designed in such a way that the knowledge and skills acquired in one level because a pre-requisite for the next level. For example, addition subtraction, multiplication and division. The intention of curriculum division. The intention of curriculum development division (CRDD) is to develop basic school Mathematics syllabus that will help students become numerate, accurate and precise in thought. This is in line with National goals of education Ghana. As much as this could be 
a noble desire of curriculum developers, a student may complete his/ her basic school certificate examination without necessary being numerate, accurate and precise in thought. But that does not mean such a student has not learnt Mathematics at all. His/her Junior High school Education. Macnab and Cummine (1986), state that, learning of Mathematics is a continuous process and is a continuous process and is not limited to the classroom experience only. With all the emphasis given too Mathematics by policy makers making it a core subject studied at the Junior High School. Students' performance in the examination has registered various inequalities in the basic education certificate examination (BECE).

The 2017 (BECE) examination results show that $55 \%$ of the boys pass Mathematics while $45 \%$ who failed were girls in the Krachi East Municipality

Results indicate that boys perform better than girls in the results above. Girl can perform as well as the boys so long as they are given an enabling environment of learning Mathematics. Stereo typed perception of the gender should frown by policy makers and stake holders. Boys do better in areas dealing with measurement and problem- solving (costello, 1991). Since 1960's gender differences in Mathematics performance have been a major topic in educations and Mathematics research.

This study entails a gender comparative analysis of students Mathematics performance in the Krachi East Municipality. Explanations for this variation could be attributed to social factors such as socio - economic background, teacher student relationship, role models for female studies encouraging female anxiety, continues.

Stating the problem, policy makers and stake holders try all their possible best to invest in the basic education of children in the Krachi East Municipal of the Volta Region of Ghana. How even despite the emphasis given our education towards the reallocation of United Nations Millennium Development Goals (MDGs) to achieve gender equality by 2015 there are still few challenges confronting females in the learning of Mathematics. Since this problem persist there is gender inequality in science and Mathematics occupations, health care and technology occupations. Several attempts have been made by ministry of education and non-governmental organizations to resolve gender disparity gab that this study on gender differences in pupil's performance in Mathematics at Krachi East Municipality intend to investigate.

\subsection{Statement of the Problem}

Does the study and quality performance in mathematics among pupils in basic schools-and thus any other level of studies in mathematics have any relationship with their gender? This problem has on several platforms been conflicted with peoples' beliefs and perceptions where some do expect a specific gender to perform well enough in the subject than the opposite. The researcher therefore decided to question pupils on their performance and perception on the subject matter; as well as sought information from those in charge of teaching the subject-Mathematics.

The purpose of this research was to identify gender disparity in pupil's performance in Mathematics in Krachi East Municipal.

The study is aimed at achieving the following objectives;

- To identify gender related factors that influence performance the study of Mathematics in basic schools.

- To identify teacher perception about boys and girl's ability to understand Mathematics concepts.

- To adopt measures to encourage boys and girls towards improved performance in mathematics at the basic school.

The findings from this study, will contribute to a better performance in the study of mathematics in our basic schools and findings in this research work as well will ensure immense contribution to the area of Mathematics in Ghana. The research will help class room teachers to improve their methodology and to improve the performance of pupils at the basic level. This will help basic school teachers to avoid partiality in their bid to deliver in Mathematics lessons in the basic schools.

\section{Materials/ Methods}

\subsection{Research Design}

The researchers are using case study. According to Cohen and Maion (1991) the distinguishing characteristics of a case study is that there is a sample size of one. Researchers using this design are generally interested in examining the case as much details as possible. Questionnaire, interview, personal observations were used. The purpose of the researchers is to survey the gender disparity of boys and girls and the teacher in the school.

In the four selected basic schools in the Krachi East Municipality, the questionnaires were personally delivered to the teachers and they were asked to submit the filled questionnaires to the researcher within two days. In most cases this arrangement was not honoured and the research went around personally to retrieve the questionnaire after waiting in vain to get questionnaires back. It took the research four days to retrieve to retrieve the questionnaires administered to teachers.

In the classes of the pupils, the researcher conducted a suring in the afternoon in other not to disturb instructional time. The selected pupils or respondents were group in one class. They were then carefully brief about the purpose of the exercise. In addition, the research read instruction and took them through item by item averagely it took them $30 \mathrm{~m}$ The target population was made of thirty (30) teachers and ninety pupils. The teacher population of thirty (30) consist of twenty (20) males and ten (10) females were selected. It was the intention of the researcher to use exact twenty percent of the student population in each class but because of an attempt to have a fair representation of the serves purposive selection had to be made in some cases. 
The teacher population was made up of thirty teachers of twenty males and ten females. The five classes used for the survey has population of 146 male student and 54 female students out of which 75 male students and 25 female students making a total of 100 were randomly selected as the sample for the survey.

\subsection{Theory/ Calculations}

\subsubsection{How Children Learn Mathematics}

Behavourist see learning in terms of connections between response and reinforcement. They place great stress upon the role played by the environment. Structured the environment well and learning will follow. Teaching is something done to the child. It is a process through which the child is put to obtain certain desired behaviours. The developmentalist on the other hand, believe that, in learning the mental processes of the child must be taken into account. The child cannot learn the same content as an adult and individual child will differ in the way they learn. In other words, learning is a personal experience and the job of the teacher is to facilitate this process. This latter approach lays much emphasis upon the way in which the individual interprets and tries to make sense of his environment Skimp (1985). The individual is not seen as mechanical products of his environment but as an active agent in the learning process. Deliberately trying to process and categorize the stream of information fed into him by the outside world (jl martin 1993).

Behaviourist theory of learning

Behaviourist psychology is one of the two basic schools of learning theories dominated educational psychology since the beginning of the twentieth century. To the behaviourist of learning is a connection between response and reinforcement.

According to skemp (1986), behavourist focus on the connection between stimuli received and responses this played by the organism or learner. For behaviourism, a new behaviour through conditioning early behaviourist like Edward and L Thorndike, B.F Skinner, Pavlov and Robert.

8The American Psychologist, Skinner come out with concept of operant conditioning in the (1950s) and (1960s). Skinner carried out experiments where rats and pigeons were enticed to press or peck a lever in order to obtain pallets of feed as examples of operant conditioning there were meant to gradually shaper an appropriate behavior into a desired outcome.

Reinforcement: is defined as an event, which increases the frequency of the response it follows. Reinforcement such as punishment is also intended to redirect pupils' behavior from an undesirable one to a desirable one to a desired behavior from an undesirable one a desired frequent reward make responses stronger. Praise and other reward follow a favourable result. That is when a desire change in behavior occurs in a child. Punishment and scolding follow an unfavorable result. Behaviorist believe in the principle that behavior that is positively reinforced will reoccur: and intermittent reinforcement is particularly effective Mathematics Anxiety:

Anxiety: is a state of a usual caused by a threat to the wellbeing of an individual. An anxious person feels endangered in some way and he is tensed and ready to respond schools in wales girls were more likely than boys to report feelings of anxiety and a lack of confidence in Mathematics.

Honas ad Smart (1995) see lack of confidence to be the main reason for girl's low participation in Mathematics. Ma and Kishor (1997), found that, confidence, which is a major component of self - concept correct latest positively with achievement with correlation coefficients larger than 0.40 at basic level Fennema and Frank (1992) also indicated that confidence in Mathematics learning corrects highly with achievement. An analysis of the educational longitudinal study of 1988, revealed that, eight grade girls tended to have less interest in Mathematics as a field of study (morin 2003)

\subsubsection{Self Confidence}

Self-confidence is one of the attitudinal vanab which seems to influence pupil achievement and participation in Mathematics. Hannulaetal (2004) in their longitudinal study on self-confidence, indicated that the learning of Mathematics is influence by the pupils Mathematics related beliefs. Especiallyself- confidence.

Baeetal (2000) also argue that achievement gaps appear more closely related to attitudes than to course taking. Based on their analysis of national assessment of Educational Progress (NAEP) data trend, Bacetal (2000) found out that, females are less likely than males to think, they were good at mathematics. A study conducted by Cann (2009). Show that in all the schools in wales girls were more likely than boys to report felling of anxiety and lack of confidence in Mathematics.

\subsubsection{Gender}

Early adolescence is a critical time for a girls' development of academic interests and attitudes. Many girls think that being bright is in conflict with being popular high level of academic success can easily be in direct conflict with the social aspects of adolescence concerning learning opportunities, students in lecture and Mathematics performance (lec 1996) Fennema and franke (1992) have suggested that, learning habits that involve working independent on high level tasks may enable some pupils to do better in Mathematics and science. Evidence also shows that; mass and females have different learning style and that females excel at a higher rate when learning Mathematics through roles. They pointed out that young girls are socialized to be dependent. And they receive more protection and more assistance in doing. Task from their parents and each than boys receive. As a result of the reinforcement of dependent when children enter school females tend to be more dependent on others and males tend to be more self-reliant. Females as grade 6 - 7 rate being popular and will liked as more important than being perceived as competent or independent, Boys on the other hand are 
more likely to claim independence and competence as importance. It is very dear that both girls and boys have learned to equate maleness with opportunity and femininity with constraint (Sadker and sadker 1994)

\subsection{Social Economic Background}

Socio economic background is one of the determinants is one of Mathematics achievement. Research shows that parents' annual income is correlated with student's Mathematics achievement scores (eamon, 2005 Janynes, 2002; Hochschild, 2003; Mcneal, 2001). Social economic status was found significant in primary mathematics and science achievement scores (Mas Klinger, 2000). Research indicates that, parents with higher socio-economic background are more responsible din their children's education than parents of lower socio-economic background. This greater involvement results in development of positive altitude of children toward school classes and achievement (Epsein 1987: lareau 1987 Stevenson\&Bakar, 1987) it is believed that low socio-economic background negatively influences academic achievement. This is because it prevents students from accessing atmosphere at home (possible disruption in parenting or an increased likely hood family conflicts) (Majorribank, 1996 Jeynes, 2002). For these reasons, socio economic background of a student is a common factor that determines academic achievement.

\subsection{Heredity}

Heredity is an interesting factor; supposing the parents were exceptional in Mathematics, would that have an effect on Mathematics ability? Beck with (19830 reports that two studies conducted since the publicity of achievement and gender in Mathematics, which seem to undercut the entire foundation for the hereditarian point of view which have received little or no attention. It is further reported by back with in 1993 that materials such as heredity are of no Match to the external factors such as society and socio-economic status. In contrast to the sum socialization explanation it is reported that, heredity differs between the saxes - for example the inheritance of a particular sex - linked recessive gene as important determinants of Mathematics ability (Alken 1987). It is also reported that the biological factors that been suggested as important in Mathematical ability are hormone difference modes of teaching Mathematics for the two sexes.

\subsection{Parents Education Level}

A study conducted by Coleman (1966) demonstrated that student achievement was correlated highly with family background factors such as income parent's educational attainment and family structure. A child's attitude toward education may be shaped by the parent's attitude toward education or parent's level of education Schewartz (1999) suggested that parents or guardians may be illiterate or have very little education and therefore, not see the importance of doing well in school and furthering education. They may not understand why it is important level course as they progress through school.

Although students can receive support and passive reinforcement at home due to lack of awareness from parents. Campbell etal (2000) analyzed the highest level of education of either parents. Results on parent education level are available back to 1978 in the area of Mathematics. In each subject and each age group. Students who reported higher parental education levels tended to have higher average scores.

Societal altitudes and expect by the time a student joints for one, his/ her parents, who to a great extent influence his/ her perception of learning in school in general and specifically learn of Mathematics. Orion (2007) attributes the notice able boys and girls. The author asserted that influence of society and from the environment affects mathematics development of student at various levels among boys and girls. Boys and girls are socialized differently while playing children games. Boys are engaged in more vigorous activities while girls take more passive roles.

\subsection{Teacher Factors}

Impact of teachers' professional training on students' achievement is a major factor. There is common thought that professional qualification of a teacher is a very essential merit of every effective teacher though some studies indicate otherwise. Base and co-hen (1999), were of the view that teachers should have an in-depth understanding of meanings and connections in subject matters and not just procedures and isolated information lack head and Komenan (1980). In a review of teacher quality on the achievement of students noted that, $60 \%$ of 60 studies that examined the effect of teacher education on student behavior found positive relationship. However, the rear divergent views on the impact that, a teacher training has on student's achievement in Mathematics. The findings of different research on the relationship between teacher training and student achievement in Mathematics are contradicting. Some researchers in Mathematics education indicate that student's achievement is a function of teacher education programs. Researchers who are of this view assume that when teachers of mathematics are well tramped, the students they teach will also achieve more in Mathematics. Those with the opposing view see teachers. Training to have very little influence on students' achievement in Mathematics.

Some research findings have indicated that, the training of Mathematics teachers positively relate to student learning out comes in the subject.

Bressoux (1996), using a quasi- experimental design, found that teacher professional training in Mathematics Darling Hammond (1992) reviewed over one hundred studies on the subject and concluded that fully prepared (trained) teacher are more effective in the class room and their students demonstrates the larger achievement gains than those teachers unprepared.

\subsection{Teacher Related Causes}

Poor lesson delivery is when teachers are unable to prepare adequately in the delivery of lessons. The lessons become uninteresting and very boring. A lot of student feel that their precious time would be wasted. To a large extent a 
lot of teachers care less about what happens what happened in their classroom students may be dozing off while classes are in session looking boring and uninteresting discouraging pupils in the classroom when they are to deliver their lessons. The lessons do not become lively and therefore kill the interest in Mathematics lessons in ability of teachers to attend classes: this had to do with the failure of some teachers to attend classes regularly. Student are likely to pounce on this opportunity and stay away from classes.

In explaining the large classroom -level differences in student achievement in Mathematics.

Hill and his colleagues highlighted the role of teacher quality and teacher effectiveness. They had evidence of substantial difference between school on teacher attitude to their work and in particular their moral (Hill 1994) and this supported the view that "it is primarily through the quality of teaching and effective schools make a difference" (Rovee\& Hill 1994) in further work that examined the impact of teacher professional development on achievement they gain argued that differences between teachers help explain much of vacation in Mathematics achievement (Hill \&Rowee, 1996: Hill \&Rowee 1998).

However, alternative explanations for the large classroom -level differences were also provided by Hill and his team. They pointed to the possibility that classroom level pupil management practices such as streaming and setting accounted for the class effects. This was not pursued by the alethors who stated that in all the schools they survey the class were of mixed ability (Hill, 1994: Rowee\& Hill, 1994) another possible was an under adjustment for initials difference that is they did not control adequately for prior achievement differences. A further explanation considered was the possibility of inconsistency in teacher ratings use in the measure of student achievement in Mathematics. This possibility was also deemed by Hill colleagues as unlikely to have had a major bearing, through its influence was not ruled out. However, the authors did not use, argue for the use of more objectives independently assessed Mathematics tests.

In an effort to understand the factors associated have focused on many factors associated with mathematics achievement researchers have focused on many factors. (Beaton \&Owyer, 2002) Kellaghan\&Madaus, 2002: Kifer: 2002). The impact of various demographic social economic and educational factors on student Mathematics achievement continues to be of great interest to the educations and researcher. For instance, Isrealetal (2001) concluded that parents' socio-economic status is corrected with a child educational achievement. Another study by Jensen and Seltzer (2000) show that factors such as individual study, parent role and social environment had a significant influence on further education decision s and achievement of young students: in another study Meece Wighted \& Eccles (1990) investigated cognitive motivation variables that influence high school student decisions to enroll in advanced Maths course their findings revealed that Maths ability perceptions affect students value of Maths and their expectations for achievement.

A growing body of research provides additional factors which could have an impact on students' achievement such as gender, family structures parents' educational level. Social economic background. Parent and students' attitude towards school and parent involvement (cambelletal 200: Epstein: 1991: Fenne Ma \$ Sheman; 1976, 1986, felicity. 1997). Three factors in math achievement, are divided into sub factors; Demographic factors (gender, socio Economic status, parents' educational levels), instructional strategies and techniques.

\subsection{Student-Teacher Interactions}

One of the most important factors that need to be taken into consideration in the teaching and learning of Mathematics is student -teacher interaction.

According to a Journal from the national council of teacher in Mathematics (1998), they stated that, more than any single factor, teachers have a way of influencing what Mathematics students learn and how they leant it. Part of the constructivist model of learning is of the view that, student construct Mathematics knowledge as a product of interaction in social content (put num, Lampert and Peterson (1990) as conn and Vackle (1996), stated in their book knowledge in Mathematics we consider student mathematics knowledge to be social through participation in communities practice.

The Journal from the national council of teachers in Mathematics (1991) recommendations for what a teacher can do to encourage the development of community of practices elude, help pupils to work together to rely more on themselves to reason Mathematically to solve problems applications. More recently the NCTM (2202), state that, the view that teachers' action is what encourage the students to thing of the questions and solve the problems Mathematically.

School and classroom effectiveness placed so much emphasis on the ability an so all backgrounds of students shape academic performance and suggested that school had little direct effect on student achievement Coleman etal (1966), for example in a major study of us schools seamed to cast doubt on the possibility of improving school achievement through reforms to schools.

\section{Results/ Discussion}

\subsection{Introduction}

This part of the research dealt with findings and discussions of results obtained from the data analysis. It involves the exploration of data by means of summary statistics (specifically frequencies and percentages).

Microsoft Excel and SPSS software were used in the analysis of the data gathered where frequencies and percentages were used in discussion of the various findings with tabular and graphical display of responses items. 


\begin{tabular}{|c|c|c|}
\hline Items of concern & Frequency & Percent \\
\hline Use of Activity Method of teaching mathematics & 70 & 70 \\
\hline Encountering challenge with chosen method & 20 & 20 \\
\hline Objectives of Instructional method met & 70 & 70 \\
\hline Use of teaching and learning materials & 80 & 80 \\
\hline Do you give pupils questions to practice during instructional time? & 75 & 75 \\
\hline Equal attention to both boys and girls in class & 75 & 75 \\
\hline Equal distribution of questions to both sexes in class & 70 & 70 \\
\hline
\end{tabular}

Table 1: Distribution on Teachers' Responses to Analyze the Key Items in Teaching and Learning. Source: Authors Field Work 2018

Results from table1: above indicated that apart from the fact that teachers sometimes $(20 \%$ of the times) do encounter some challenges in their approach to teaching or method of delivery on mathematics topics in class, teachers also in most instances (averagely 75\% of the times) however do engage activity method of teaching mathematic as well as the use of teaching and learning materials (though inadequate) by giving out sample questions for pupils to practice during instructional time in which cases the objectives were met.

Furthermore, teachers' pay equal attention to both boys and girls in class to a high extent of seventy-five percent (75\%) and; questions are distributed to both sexes equally.

\begin{tabular}{|c|c|c|}
\hline Qualification & Frequency & Percent \\
\hline Certificate & 0 & 0 \\
\hline Deploma & 13 & 43 \\
\hline Degree & 15 & 15 \\
\hline Masters & 2 & 2 \\
\hline Total & 30 & 100 \\
\hline
\end{tabular}

Table 2: Distribution to Analyze Key Factor-Qualification of Teachers

Source: Authors Field Work 2018

The responses with regards to qualification of teachers in the selected schools in the municipality are shown in the table 2 above where no teacher is a certificate holder. Also, it was evident that on the average, 43 percent of teachers were diploma certificate holders whereas 50 percent were degree teachers. However, a few portions of the teachers of 7 percent have advance certificates (master's degree).

The above report on teacher's qualification established the fact that all the teaching staff ( of $100 \%$ response) were all equipped by the standards of the Ghana Education Service to deliver a quality services to the pupils.

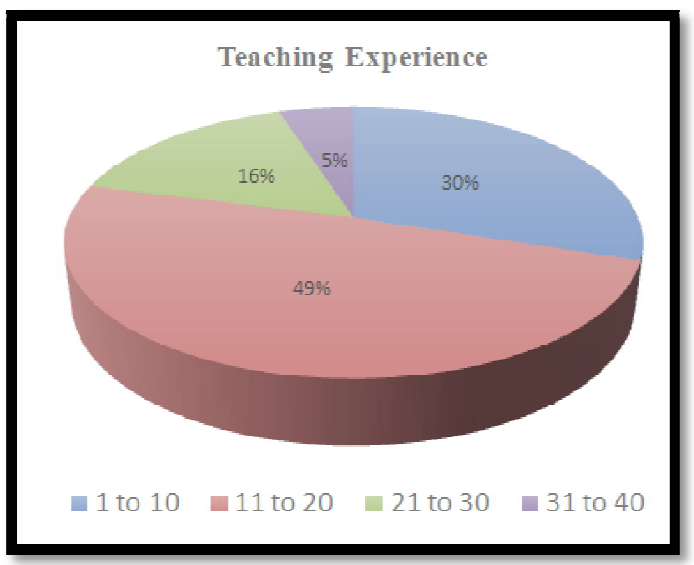

Figure 1: Teaching Experience of Teachers

The figure above establishes the experiences relating to period in the teaching profession of teachers in these four schools investigated.

Findings shows that majority of the teachers representing forty-nine percent (49\%) have been teaching between eleven-to-twenty years inclusive. Also, sixteen percent (16\%) of them have been teaching between 21years to 30years; thirty percent (30\%) have been teaching for at most 10 years whereas a least proportion of the teachers representing five percent (5\%) have been teaching for at least 31 years.

It is thus evident that almost all the teaching staff was very experience in their teaching profession. 


\begin{tabular}{|c|c|c|}
\hline Reasons & Frequency & Percent (\%) ) \\
\hline Financial problem associated with poor in class & 62 & 60 \\
\hline Basic needs of girls provided by parent & 50 & 50 \\
\hline Girl child classes attendance & 40 & 40 \\
\hline $\begin{array}{c}\text { Girl child contribute to class discussion in classes } \\
\text { compared to the boys }\end{array}$ & 35 & 35 \\
\hline
\end{tabular}

Table 3: Distribution to Analyze Key Possible Challenges of Girls in School Source: Authors Field Work 2018

Table 3 shows that $60 \%$ of the times, girls are faced with financial problems which is believed to have an influence on their health and wellbeing is school. Responses also indicated that fifty percent (50\%) of the needs of girls supposed to be provided by parents were not attended to and this in effect will decline the performance of girls in class since they result to having a divided attention in class. Thus, on the average fifty-five percent of the time spent in school, girls face challenges with regards to financial and other basic need supposed to be provided by parents.

It was further realized that sixty percent (60\%) of the times, girls do absent themselves from classes as well as make little contributions to discussions in classes.

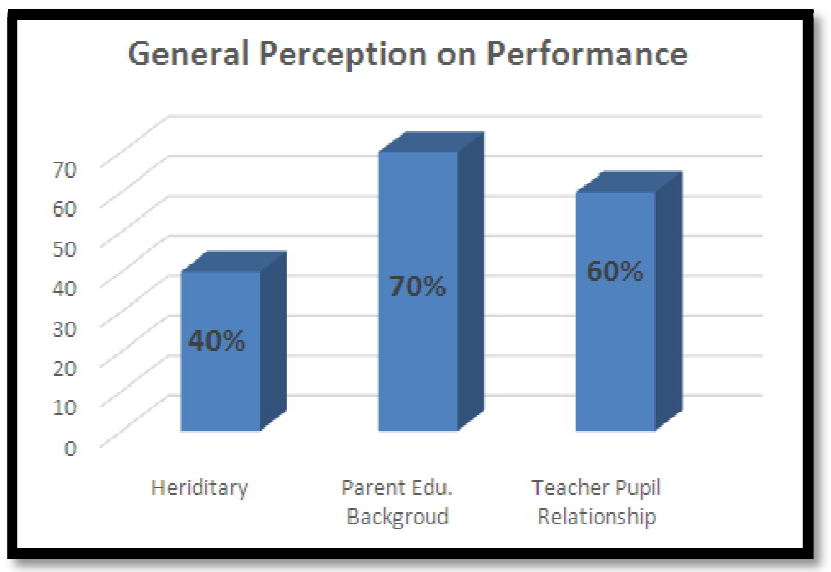

Figure 2 General Perception on Performance

Figure 2 above establish the fact that to a very high extent of $70 \%$, pupils admit the fact that their parents' educational background place a vital role in their ability to perform well in school and in mathematics. A Pupil further stated that a higher educational level with regards to their parent will enhance a better performance since they might likely assist them during their studies at home. Hereditary however is believed to play but a little impact ( $40 \%$ influence) on pupils' performance in mathematics in school. Further, it was evident to a very high extent of sixty percent (60\%) that a very good relationship between a pupil a subject teacher could foster an improved performance for pupils and the school at large.

A follow-up question on whether or not teachers give more exercises in class showed that seventy percent (70\%) of the times, teachers responded they give more assignment. Thus, a very good teacher-pupil relation will indeed ensure a very good performance in school and thus in mathematics studies.

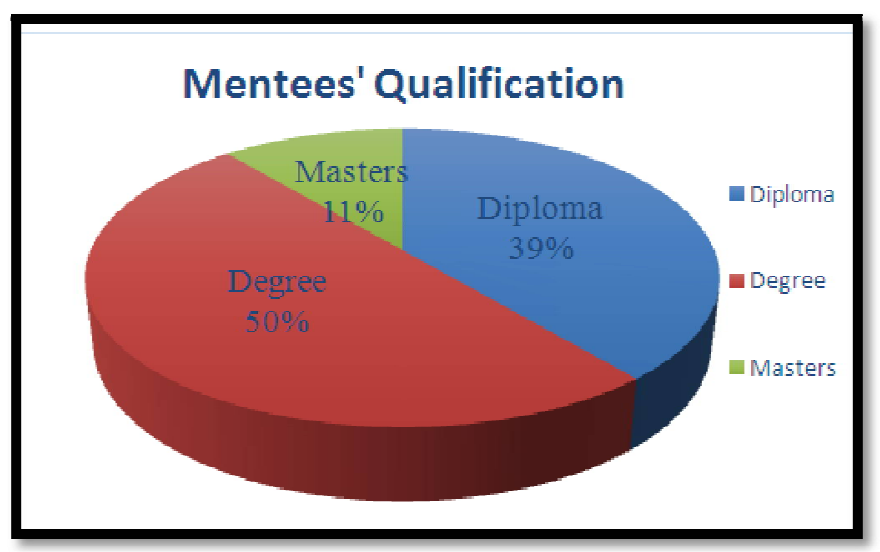

Figure 3: Mentees' Qualification

The Figure 3 above shows the qualifications of the teacher mentees teaching respective subjects with respect to their field of specialty. It is thus evident that thirty-nine percent portion of the mentees hold a diploma certification in teaching whereas Eleven percent have masters' degree. The vast majority however are degree holders. All teachers questioned at the time of this research were professional teachers. 


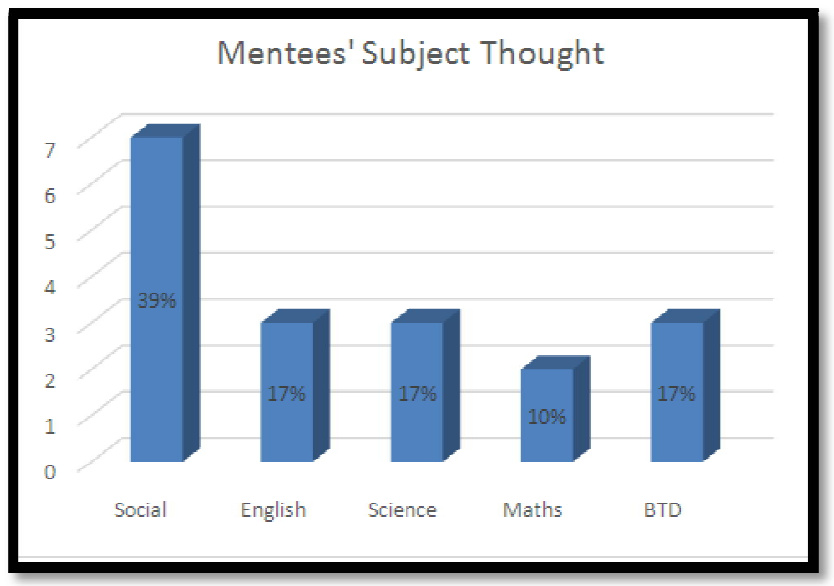

Figure 4: Subject Taught by Mentees

The figure 4: above as well give evidence on the fact that there is but fewer mathematics teachers in all four schools investigated in this research. That is only ten percent of the mentees posted to these schools teach mathematics. Another finding from a question in the researchers' questionnaire on delivery of mathematics as a subject showed that mathematics lessons were the least delivered lessons (30\% impact) compare to other subjects taught in these four schools.

\begin{tabular}{|c|c|c|}
\hline Question Items & Frequency & Percent \\
\hline Mentees use teaching and learning materials & 70 & 70.0 \\
\hline Use of different pedagogies in teaching & 70 & 70.0 \\
\hline Attendance of mentees & 60 & 60.0 \\
\hline Impact in pupil's mathematics result & 70 & 70.0 \\
\hline Mentees perform well in mathematics than other schools & 60 & 60.0 \\
\hline Mentees motivate pupils & 70 & 70.0 \\
\hline Impact of mentees & 70 & 70.0 \\
\hline instructional objectives achieve & 70 & 70.0 \\
\hline use of activity method & 70 & 70.0 \\
\hline Desire to have mentees every year & 70 & 70.0 \\
\hline mastery over mathematics & 70 & 70.0 \\
\hline Teaching delivery pace & 70 & 70.0 \\
\hline Immediate feedback & 50 & 50.0 \\
\hline Anxiety managed in learning mathematics & 55 & 55.0 \\
\hline Average & 66 & $66.1 \%$ \\
\hline
\end{tabular}

Table 4: Mentees Teaching Appraisal

Table 4.4 above establishes the fact that mentees to a high extent of $66.1 \%$ were good at delivering content of subjects taught using teaching and learning material by exploring different teaching pedagogies to impact pupils when teaching.

Mentees as well demonstrated mastery over the course content with a good delivery pace. They were also believed to have been performing well in these three schools than the other schools in the municipality.

However, it was also realized that mentees to an extent of forty percent (40\%) of the times fail to write their lesson note which was intended to get them prepared before start of lessons as well as guide them during lessons. It was also noted that mathematics compare to other subjects was the least frequent subject studied in these four-school due to the least number of mathematics teachers present on the staff.

\section{Summary/Conclusion/Recommendations}

\subsection{Summary}

The study set out to assess gender disparity in pupil's performance in Mathematics in Krachi East Municipal. Specifically, the study was undertaken;

- To identify gender related factors that influence performance the study of Mathematics in basic schools.

- To identify teacher perception about boys and girl's ability to understand Mathematics concepts.

- To adopt measures to encourage boys and girls towards improved performance in mathematics at the basic school.

The researcher employed the use of questionnaires to obtaining information for analysis. In order to achieve the above objectives of the study, data on teachers and mentees qualifications, experiences and approaches to teaching and learning were obtained; socio-demographic characteristics (gender, age) of pupils, mentees and teachers were obtained as 
well as pupils performances based on participation during mathematics lessons. The entire data for the study was collected and analyzed in year 2018.

A total of 130 responses were considered in the analysis. This number comprised 100 pupils and 30 teachers all of Dace demonstration school, Dambai RC JHS and Lakeside JHS in the Krachi east municipality. Data collected was analyzed and summarized and presented using frequencies and percentages.

The main findings are as follows:

- $20 \%$ of the times, teachers do encounter some challenges in their approach to teaching or method of delivery on mathematics topics in class.

- Teachers also in most instances (75\% of the times) do engage activity method of teaching mathematic and the use of teaching and learning materials to meet their goals.

- Teaching and learning materials are inadequate.

- Teachers to a high extent of seventy-five percent (75\%) pay equal attention to both boys and girls in class.

- All the teaching staffs (100\%) were experienced, qualified and equipped by the standards of the Ghana Education Service to deliver a quality services to the pupils.

- $55 \%$ of the times, girls do face challenges with regards to financial and other basic need supposed to be provided by parents.

- $60 \%$ of the times, girls do absent themselves from classes as well as make little contributions to discussions in class.

- $70 \%$ of pupils admitted parents' educational background plays a vital role in their ability to perform well in school and in mathematics stating that a higher educational level of parent will enhance a better performance.

- A very good teacher-pupil relation will indeed ensure a better performance in the study of mathematics

- All mentees were professional teachers

- Mathematics compare to other subjects was the least frequent subject studied (based on time table structured) in these four-school due to the least number of mathematics teachers present on the staff $(10 \%$ mentees teaching mathematics).

- Mentees as well demonstrated mastery over the course content with a good delivery pace.

- $40 \%$ of the times, mentees fail to write their lesson note which was intended to get them prepared before start of lessons as well as guide them during lessons.

\subsection{Conclusions}

Base on the findings of the study, four broad conclusions could be drawn:

- Teachers motivates and pay equal attention to both boys and girls in the delivery of course content in class and thus will not expect a disparity with regards to gender in the way pupil perform when assessed in any mathematics topic taught.

- A higher portion of boys perform well and at times better than their counterpart girls since most of the girls do face challenges than boys with regards to finances and other basic need supposed to be provided by parents. Girls tend to absent themselves from classes and make little contributions to discussions in class

- Both boys and girls ought to develop a positive passion towards the study of mathematics and must be punctual in class.

\subsection{General Recommendations}

Based on the analysis of results, we thus recommend that parents ensure the provision of the needs of their wards especially the girl-child for a better performance. Governing bodies as well as policy makers should provide adequate materials for teaching mathematics and also encourage pupils in the study of mathematics in these schools.

\section{Contribution to Knowledge}

This study made at least one relevant and important contribution to Knowledge in one main respect by identifying the fact a very good teacher-pupil relation will indeed ensure a better performance in the study of mathematics in schools.

\section{References}

i. Campbell P.B (1995), Redefining the "girl problem" in mathematics in W.G Secada. E. Fennema

ii. \&L. B Adjian (Eds), New directions for equity in mathematics education (PP, 225 -241)

iii. Cambridge: Cambridge University Press.

iv. Beaton. A. E \&O'Dwyer L.M. (2002) separating school, classroom and student variances and their relationship to socio economic status. In D.F Robitaille \& A.E Beaton (Ed's) secondary analysis of the TIMSS data (PP. 211-231). Boston, MA: Kluwer Academic Publishes:

v. Kifer, E. W (2002). Students' attitudes and perceptions. In P.F Robitaille \& A.E Beaton (Eds).

vi. Secondary analysis of the TIMS data. Boston: Kluwer Academic publishers. Journal for national council of teacher in mathematics (1998).

vii. Stevenson D.L. \& Baker.D.P (1987). The family-school relation and the child school performance. Child development, 58, 1346-1357.

viii. Marjori banks, K(1996), family learning environment and students' out comes: A review.

ix. Journal of comparative family studies, 27,373-394 
x. Epstein, J.L (1987), parent involvement what research says to administrators, Education and

xi. urban society, 19:119-136

xii. Ma, X, \& Klinger, D, A (2000). Hierarchical linear modeling of student and school effects on academic achievements Canadian journal of education, 25,41-55 